\title{
WASTEWATER REUSE CRITERIA IN GREECE
}

\section{A. ANDREADAKIS* \\ E. GAVALAKI \\ D. MAMAIS}

\section{A. TZIMAS}

Selected from papers presented at the $7^{\text {th }}$ Conference on Environmental Science and Technology,

3 -6 September 2001, Ermoupolis, Syros island, Greece.

\begin{abstract}
Sanitary Engineering Laboratory, Department of Water Resources Hydraulics and Maritime Works,

School of Civil Engineering,

National Technical University of Athens

5, Iroon Polytechneiou street, Zografou 15773, Athens
\end{abstract}

*to whom all correspondence should be addressed: fax: + (30) 2106528078, 2107722899

e-mail: andre1@central.ntua.gr

\begin{abstract}
The sustainable management of water resources often requires the identification of wastewater as a valued source of water. Although the benefits of wastewater reuse and reclamation have increased significantly in Europe because of the advances in effectiveness of wastewater treatment and disinfection technologies there is currently no legislation nor guidelines regarding reuse. It is well known that there is a great variation of wastewater reuse quality criteria applied, mainly related to significant differences in socioeconomic conditions, environmental policies, available water resources. In this work the parameters that affect the wastewater reuse criteria in Greece are evaluated, concerning among others reuse priorities, available treatment plants and effluent characteristics and recommendations are made for developing future guidelines or regulations for Greece in relation to reuse practices (agricultural, urban, etc). The intention is not to propose an unquestionable and rigid set of standards, but to present them on the basis of the rationale developed, in order to form a basis for further consultation, involving all the interested parties. The recommendations are presented in relation to the different types of reuse, with appropriate specific standards and recommended treatment systems wherever applicable.
\end{abstract}

KEYWORDS: Wastewater reuse, Greece, guidelines, criteria, wastewater treatment

\section{INTRODUCTION}

With respect to wastewater reuse and reclamation, Mediterranean countries share many features and characteristics related to climate, available water resources and social and economic conditions, which more specifically correspond to relatively long summer and a rather short rainy season during winter and early spring, water shortage related to droughts as well as intensive agriculture and tourism which are the main eco- nomic activities and shortage of funds for both capital investments and operating costs in the public municipal sector (SEL, 2000).

These features dictate that intensive and safe wastewater reuse schemes should be practiced on a large scale in the Mediterranean countries, not only due to the increased need for water in irrigation, but because such schemes provide in some of the countries an important 'positive incentive' 
to promote public investment in wastewater treatment and pollution abatement facilities, and continuously maintain and operate these facilities. Needless-to-say that some of the above features (among them tourism and exporting of products) dictate the need to maintain a non-compromising high quality of any treated effluent and reclaimed wastewater to be reused and to maintain the highest public health standards related to wastewater reuse and reclamation.

Despite these common features, important differences should also be recognised. In some countries wastewater treatment is dictated by strict effluent discharge limits, irrespective of reuse, while in others the main incentive for treatment is related to water reclamation practices. This leads to a situation of different starting points for various countries, with respect to the treatment needed for reuse. Although water shortage is a common feature, the magnitude of the problem varies. Countries like Israel, Jordan, and Cyprus face a severe problem, throughout their territories, while in other countries such as Greece, the problem of water shortage is less acute and rather local (e.g. mainly in the islands and along the east coast). Socio-economic conditions may be different in various countries considering the a bigger shortage of funds for capital investments and operating costs in the less industrialised and developed countries of the region, while EU funds are important for countries like Greece. With respect to experience countries such as Morocco, Jordan, Egypt, Tunisia, Malta, Cyprus, Greece and Spain, several major projects are already in operation or under planning, while in Israel, shear necessity has dictated the construction and operation of wastewater reuse schemes of a large scale, mainly where the reclaimed wastewater is reused for agricultural irrigation (SEL, 2000). Other countries, such as France and Italy are seriously considering wastewater reuse, and active research, as well as demonstration-scale endeavours, are being carried out (Asano, 1998).

Due to these differences a uniform approach with respect to reuse guidelines and regulation presents serious difficulties. Egypt, Jordan, Tunisia, Palestine, Marocco, Syria form a group of countries in great need for extensive reuse practices, which however have to be feasible under the social and economical conditions prevailing, i.e. shortage of funds, limited experience for both construction and operation of sophisticated treatment systems, inadequate infrastructure including sewers and wastewater treatment plants, (due also to the relatively relaxed discharge requirements). Strict reuse standards, such as the ones proposed by California, EPA and other states of the USA (USEPA, 1992), as well as industrialised countries are not easily achievable in these countries, due to their economical, technological and institutional conditions. The WHO guidelines (WHO, 1989), are significantly less strict, with the intention to introduce some treatment of wastewater prior to crop irrigation, particularly in developing countries. WHO guidelines are therefore more appropriate for these countries, at least as an interim measure until there is an ability to produce higher quality reclaimed water.

The situation is different with another group of countries, including Greece, Cyprus, Israel and Malta. Due to a higher stage of development, more available funds, existing infrastructure and more advanced legislation regarding environmental pollution control, it is unlikely that the WHO guidelines can form the basis for their reuse regulations. This is also the case for other South European and Mediterranean countries (Italy, France, Spain, Portugal). The tendency to adopt stricter standards than the ones proposed by the WHO guidelines is reflected in recently developed regulations (Spain, Israel, Cyprus, Italy) and the strong criticism of existing standards based on WHO guidelines (parts of Italy, France).

\section{THE CASE OF GREECE}

The development of appropriate guidelines or regulations for water reclamation in Greece, should take into consideration the following factors:

- Greece belongs to the group of developed countries and, although not as economically strong as many countries of that group, can and is expected to allocate significant funds for health protection and environmental pollution control.

- Greece, as a member of the EU, has to consider harmonisation with possible future EU relevant legislation. In this context the practice and regulations of other European Countries have to be taken into consideration.

- Due to the existing legislation concerning effluent discharge limitations, an extensive programme for construction and operation of municipal wastewater treatment plants has been 
carried out during the last 10-15 years. Currently a significant percentage of the population (about $60 \%$ ) is served by centralised wastewater treatment plants, expected to reach $80-85 \%$ in the near future. Secondary mechanical biological treatment is the minimum treatment employed, usually with full or partial nitrogen removal in about $80 \%$ of the cases (Andreadakis et al., 1997). Tertiary treatment, in the form of filtration, is practiced in some plants, but the process of upgrading other plants to tertiary treatment is an on going process. In view of this situation, restricted reuse is an already existing possibility in compliance even with strict standards, while the quality needed for unrestricted reuse can be achieved at a moderate cost, through upgrading of the existing plants.

- Water reclamation, although important in some parts of the countries, is not as critical as in many countries of the South East Mediterranean and Middle East region. Alternative sources of fresh water are usually available at reasonable costs. Water reclamation is considered as an attractive ecological concept, however its wide scale application can be viable on the condition that high quality reclaimed water can be obtained at a moderate cost, and that health risks are practically eliminated.

- Agricultural practices and institutional arrangements often do not favour the implementation of a clear-cut distinction between restricted and unrestricted applications. Thus, a major part of the reclaimed water should be suitable for unrestricted non-potable uses, with exceptional and well-documented restricted applications.

- Although irrigation seems to be the dominant type of reuse, urban reuse has a lot of potential.

- Reuse for industrial purposes is not expected to be significant in the near future. Alternative sources for cooling water are often available (e.g. sea water) and process waters, when reclaimed, can originate from in plant recycling.

- Direct potable reuse should not be encouraged. The relative availability of fresh water supplies and the excessive costs and uncertainties involved with direct potable water reuse do not justify its implementation.

- Groundwater recharge for indirect potable reuse (or augmentation of surface waters for the same purpose) should also be discouraged. Dilution and further treatment by the soil are two impor- tant additional barriers, when compared to direct potable reuse (Asano, 1998). However, the uncertainties regarding long-term health effects, although reduced, still remain. Furthermore, the need for comprehensive in situ studies and elaborate monitoring programmes requires a strong background of field data, organisational and institutional arrangements, which are to a large, extend missing (CSWR, 1975, 1987).

- Recharge of aquifers not intended for abstraction of water for drinking purposes is interesting, particularly for creating barriers to salt water intrusion along the coastline.

- The most likely mode of operation for agricultural reuse is seasonal irrigation, surface or groundwater storage is a possibility but so far in most cases this has not proved to be an economically justified option.

\section{RECOMMENDED REUSE GUIDELINES FOR GREECE}

The evaluation of the existing situation in Greece, concerning among others reuse priorities, available treatment plants and effluent characteristics, has led to the recommendations presented in this paper, for developing future guidelines or regulations appropriate to Greek conditions. The intention is not to propose an unquestionable and rigid set of standards, but to present them on the basis of the rationale developed, in order to form a basis for further consultation, involving all the interested parties.

The recommendations are presented in relation to the different types of reuse, with appropriate specific standards and recommended treatment systems wherever applicable.

\section{Agricultural Reuse}

Distinction should be made between restricted and unrestricted irrigation, on the basis of irrigated crops and modes of operation. Crops for restricted irrigation include forests and areas where access to the public is not expected, fodder, industrial crops, pastures, trees (including fruit bearing trees, on the condition that during collection the fruits do not come into contact with the ground), seed crops, crops that produce products which are processed before consumption. With respect to irrigation methods spray irrigation is not allowed. Unrestricted irrigation includes all other crops such as vegetables, vineyards, crops, 
with products that are consumed raw, greenhouses. Unrestricted irrigation allows for different irrigation methods including spray irrigation.

The minimum treatment required for restricted irrigation is secondary biological treatment and disinfection producing an effluent with $\mathrm{BOD}_{5}$ and $\mathrm{SS}$ concentrations below 25 and $35 \mathrm{mg} \mathrm{l}^{-1}$ for $95 \%$ of the samples and a feacal coliforms concentration below $200 \mathrm{FC} / 100 \mathrm{ml}$, as a median value and not exceeding $800 \mathrm{FC} / 100 \mathrm{ml}$ for $95 \%$ of the samples.

An influent with nitrogen concentration lower than $30 \mathrm{mg} \mathrm{l}^{-1}$ is required, to be achieved, whenever needed, through partial denitrification. If long term storage in surface reservoirs is foreseen for the reclaimed water, advanced nutrients removal is needed, able to produce an effluent with nitrogen concentrations lower than $15 \mathrm{mg} \mathrm{l}^{-1}$ and phosphorus less than $4 \mathrm{mg} \mathrm{l}^{-1}$. Recommended methods for secondary treatment include various types of activated sludge process, biological filters and rotating biological contactors. Other systems, including natural systems and on site systems producing effluents of equivalent quality $\left(\mathrm{BOD}_{5} / \mathrm{SS}=25 / 35\right)$ can be accepted, on the basis of adequate documentation. The minimum treatment for unrestricted irrigation is secondary biological treatment, followed by tertiary treatment (normally coagulation, flocculation, sedimentation, filtration) and disinfection, producing an effluent with $\mathrm{BOD}_{5}$ and SS concentrations below $10 \mathrm{mg} \mathrm{l}^{-1}$ for $80 \%$ percent of the samples and turbidities below 2 NTU as an average value. Feacal coliform concentrations should be below $5 \mathrm{FC} / 100 \mathrm{ml}$ for $80 \%$ of the samples, below $15 \mathrm{FC} / 100 \mathrm{ml}$ for $95 \%$ of the samples, and not exceeding $100 \mathrm{FC} / 100 \mathrm{ml}$ in any sample.

Nitrogen requirements are the same as in the case of unrestricted irrigation. Recommended methods for secondary treatment are also the same as in the case of unrestricted irrigation. Tertiary treatment may be limited to direct filtration (coagulation, flocculation and filtration) or contact filtration (coagulation, filtration followed by disinfection), provided that it is well documented that the effluent produced after secondary treatment has SS concentrations lower than $20 \mathrm{mg} \mathrm{l}^{-1}$ for $80 \%$ of the samples. Other methods of tertiary system may be adopted, provided it is documented that they produce an effluent of equivalent quality.

The standards for restricted and unrestricted irrigation are presented in Table 1.

In addition to the above requirements, further requirements should also be met related to levels of trace elements such as aluminium, arsenic, manganese, zinc, mercury etc., while the suitability of the reclaimed wastewater should be evaluated on the basis of the general characteristics of irrigation water such as salinity (electrical conductivity or TDS), infiltration (sodium adsorption ratio), ion toxicity (chlorides, boron), nitrogen, $\mathrm{pH}$ etc (FAO, 1985).

\section{Urban non potable reuse - Habitat restoration - Recreation}

These types of reuse typically include landscape areas (cemeteries, freeway landscaping, golf courses, parks), landscape and recreational impoundments, fire fighting, soil compaction, dust control, cleaning roads, sidewalks, toilet and urinal flushing, decorative fountains. Regulations often make a distinction between restricted and unrestricted urban uses on the basis of the level and frequency human contact with the reclaimed water. In terms of treatment, restricted urban reuse relies on secondary treatment, while unrestricted reuse calls for an addition tertiary treatment scheme.

The distinction between restricted and unrestricted urban reuse is a valid and safe procedure on the condition that institutional, organisational and administrative arrangements are such that can safeguard its proper implementation. The fulfilment of this condition is of questionable probability in the case of Greece. It is therefore recommended that the uniform standards corresponding to unrestricted reuse are adopted for all types of urban habitat restoration and recreational reuse. These standards and the treatment systems recommended are presented in Table 2. The requirements of trace elements and general characteristics of irrigation water must also be met.

\section{Industrial Reuse}

Reuse for industrial purposes include cooling waters, boilers and process water (WPCF, 1989). For once through cooling systems a secondary disinfected effluent with FC concentration less than $200 / 100 \mathrm{ml}$ can be used. For all other cases including recirculated cooling systems a tertiary treated effluent is the minimum requirement. Additional treatment may be needed depending on the specific requirements of each application. The proposed guidelines for once through systems are practically the same as those recom- 
Table 1. Recommended Guidelines for microbiological and conventional parameters for agricultural wastewater reuse in Greece

\begin{tabular}{|c|c|c|}
\hline & Restricted Irrigation $^{1}$ & Unrestricted Irrigation $^{2}$ \\
\hline Fecal coliforms/100 ml & 200 as median value & 5 for $80 \%$ of samples \\
\hline $\mathrm{BOD}_{5}\left(\mathrm{mg} \mathrm{l}^{-1}\right)$ & 25 for $80 \%$ of samples & 10 for $80 \%$ of samples \\
\hline $\mathrm{SS}\left(\mathrm{mg} \mathrm{l}^{-1}\right)$ & 35 for $80 \%$ of samples & 10 for $80 \%$ of samples \\
\hline Turbidity (NTU) & - & 2 median value \\
\hline Recommended treatment & $\begin{array}{l}\text { - secondary biological treatment } \\
\text { - disinfection }\end{array}$ & $\begin{array}{l}\text { - } \text { secondary biological treatment } \\
\text { - tertiary treatment } \\
\text { - disinfection }\end{array}$ \\
\hline
\end{tabular}

1 Forests and areas where access to the public is not expected, fodder, industrial crops, pastures, trees (including fruit bearing trees on the condition that during collection the fruits do not come into contact with the ground), seed crops, crops that produce products which are processed before consumption. Spray irrigation should not be practiced.

2 All other crops such as vegetables, vineyards, crops with products which are consumed raw, greenhouses. Unrestricted irrigation allows for different irrigation methods including spray irrigation.

a Recommended methods for secondary treatment include various types of activated sludge process, biological filters and rotating biological contactors. Other systems including natural systems and on site systems producing effluents of equivalent quality $\left(B O D_{5} / S S=25 / 35\right)$ can be accepted on the basis of adequate documentation. With respect to nitrogen concentrations in the effluent must be lower than $30 \mathrm{mg} \mathrm{l}^{-1}$ except in cases of long-term surface storage, where a concentration of $15 \mathrm{mg} \mathrm{l}^{-1}$ for nitrogen and $4 \mathrm{mg}^{l^{-1}}$ for phosphorus must be adopted.

$b$ Chlorination, ozonation, or other chemical disinfectants, UV radiation, membrane processes.

c Normally coagulation, flocculation, sedimentation, filtration. Direct or contact filtration can be used if secondary treatment produces effluent with SS concentrations lower than $20 \mathrm{mg}^{-1}$ for $80 \%$ of the samples.

Table 2. Recommended Guidelines for microbiological and conventional parameters for urban non-potable reuse, habitat restoration, recreation in Greece

\begin{tabular}{|c|c|}
\hline & Urban non-potable reuse, habitat restoration, recreation ${ }^{1}$ \\
\hline Fecal coliforms $/ 100 \mathrm{ml}$ & 5 for $80 \%$ of samples \\
\hline $\mathrm{BOD}_{5}\left(\mathrm{mg} \mathrm{l}^{-1}\right)$ & 10 for $80 \%$ of samples \\
\hline $\operatorname{SS}\left(\mathrm{mg} \mathrm{l}^{-1}\right)$ & 10 for $80 \%$ of samples \\
\hline Turbidity (NTU) & 2 median value \\
\hline Recommended treatment & $\begin{array}{l}\text { - secondary biological treatment } \\
\text { - tertiary treatment } \\
\text { - disinfection }\end{array}$ \\
\hline
\end{tabular}

1 Landscape areas (cemeteries, freeway landscaping, golf courses, parks), landscape and recreational impoundments, fire fighting, soil compaction, dust control, cleaning roads, sidewalks, toilet and urinal flushing, decorative fountains.

mended for restricted irrigation, whereas in the case of recirculated cooling systems, boiler and process waters the proposed standards are the same to unrestricted irrigation (Table 1).

\section{Direct and Planned Indirect Potable Reuse}

It is recommended that potable reuse of any kind is not allowed.

\section{Groundwater Recharge for Non Potable Reuse}

Groundwater recharge can be allowed in cases where it is documented that the groundwater is not used for drinking purposes. The groundwater quality should match the quality required for unrestricted irrigation and urban reuse. However, in view of the uncertainties regarding possible future uses of the aquifer, consideration should be given to prevent accumulation of organic compounds in the groundwater. Therefore adequate treatment for removal of organics should be provided, and the recommended treatment scheme in addition to secondary and tertiary stages should include advanced treatment for removal of soluble organic material (such as carbon adsorption or membranes). In cases of recharge by infiltration, through a soil layer of suitable characteristics and 
depth, removal of organics is expected to occur in the soil and the advanced treatment stage may be omitted. Irrespective of the minimum treatment requirements described, site specific hydrogeological studies should be conducted.

\section{CONCLUSIONS}

The recent need for a holistic approach with respect to water resources management, within the European Union, indirectly imposes the need for wastewater reclamation and reuse criteria, mainly in countries of the Mediterranean Region where water resources are relatively limited compared to the countries of northern Europe. At a European Union level a relevant to wastewater reuse directive is highly unlikely to appear in the near future since most of the EU countries do not face decrease of the water resources. Greece is one of the countries that has the scientific and technological background to establish wastewater reuse criteria at a national level, while at the same time the need for additional water resources in many parts of the country imposes such a need. The paper presents recommendations for developing guidelines for wastewater reuse in Greece, considering the effluent characteristics of WWTPs, the available water resources, the socio-economic conditions, the guidelines applied in different countries that have a wide experience in wastewater reclamation and reuse. The main type of reuse is related to agricultural activities, while urban reuse has to be considered as a significant alternative, mainly in urban areas of the country. Direct and indirect potable reuse should not be practiced considering the uncertainty of long-term effects, while groundwater recharge for non-potable reuse for creating barriers to salt water intrusion is an interesting alternative. The standards proposed are realistic and feasible, and can be readily achieved at a moderate cost, through upgrading of the existing plants with tertiary treatment.

\section{ACKNOWLEDGMENTS}

In the frame of a Five Year Development Assistance Programme in the field of the Environment (DAPE), the Sanitary Engineering Laboratory of National Technical University of Athens (NTUA) was appointed by the Ministry of Environment and Public Works of Greece to coordinate the project "Treatment and Reuse of Sewage and Sludge in the South Mediterranean and Middle East Countries". The countries involved include, apart from Greece, Egypt, Tunisia, Israel, Cyprus, Jordan and Palestine. The research team wishes to acknowledge the Ministry of the Environment, Planning and Public Works, for sponsoring the Project and the supervising committee for their cooperation, contribution and support during all stages of the programme. Additionally thanks are also due to the representatives of the participating countries whose experience and knowledge were valuable for the project.

\section{REFERENCES}

Sanitary Engineering Laboratory (SEL). (2000), Treatment and Reuse of Sewage and Sludge in the South Mediterranean and Middle East Countries, Final Report Ministry of Environment and Public Works of Greece

Asano T. (1998), Wastewater Reclamation and Reuse, Chapter 27: Indirect potable Reuse of Reclaimed Water, Water Quality Management Library, Vol. 10.

U.S. Environmental Protection Agency, EPA, 625/R-92/004. (1992), Guidelines for Water Reuse - Manual.

World Health Organization (WHO) (1989), Health Guidelines for the Use of Wastewater in Agriculture and Aquaculture, Report of a WHO Scientific Group, Geneva, Switzerland.

Andreadakis A., Gavalaki E., Fougias E. (1997), Wastewater treatment in Greece, Proceedings of Symposium for Management of Wastewater and Solid Wastes in Greece, Chalkida-Greece.

California State Water Resources (1975), State-of-the-Art, Review of Health Aspects of Wastewater Reclamation for Groundwater Recharge" Control Board, Dep. Water Resour. Dep. Health Serv., Sacramento, Calif.

California State Water Resources (1987), Report of the Scientific Advisory Panel on Groundwater Recharge with Reclaimed Wastewater, Control Board, Dep. Water Resour. Dep. Health Serv., Sacramento, Calif.

FAO, (1985), Water quality for agriculture, R.S. Ayres and D.W, Westcot, FAO Irrigation and Drainage Paper 29, FAO, Rome.

Water Pollution Control Federation (WPCF). (1989), Water Reuse, Manual of Practice SM-3. 